\title{
АНАЛІТИЧНА МОДЕЛЬ ЗУБКА ЧАСНИКУ 3 ЦЕНТРАЛЬНИМ СТРИЖНЕМ
}

\author{
Ярослав Семен, к. т. н., Олександр Пономаренко, к. ф.-м. н., \\ Олег Крупич, к. т. н., Степан Левко \\ Львівський національний аграрний університет, \\ вул. Володимира Великого, 1, м. Дубляни, Львівський р-н, Львівська обл., Украӥна, \\ e-mail:jsemen@ukr.net,olexanderponomarenko54@gmail.com,krupycholeh@gmail.com, \\ stepanlevko3@gmail.com
}

https://doi.org/10.31734/agroengineering2021.25.036

Семен Я., Пономаренко О., Крупич О., Левко С. Аналітична модель зубка часнику з центральним стрижнем Проведено теоретичні дослідження і запропоновано модель зубка часнику, сформованого на центральному стрижні головки часнику, який розглядається в декартовій системі координат як частина кулі відповідного радіуса, об'єм якої обмежений двома меридіональними площинами 3 двогранним кутом між ними та однією площиною, що лежить в основі зубка і $є$ перпендикулярною до двох інших з урахуванням діаметра центрального стрижня головки часнику, на якому сформовані зубки і який вважається циліндром певного радіуса і висоти.

Отримано аналітичні залежності, що дозволяють знайти масу зубка часнику, сформованого на центральному стрижні головки часнику, з урахуванням однорідності тіл однакової густини окремо для центрального стрижня $\mathrm{i}$ зубка, центр ваги якого лежить у площині симетрії, що поділяе зубок навпіл за висотою. Наведено розрахункову схему й отримано аналітичні залежності для визначення координат центра ваги зубка часнику з використанням методу додатних і від'ємних площ, що враховують координати центрів ваги площ кругових секторів зубка та центрального циліндричного стрижня в їх довільному поперечному перерізі.

Наведено результати теоретичних досліджень, які дозволили встановити існуючий взаємозв'язок між окремими розмірно-масовими показниками і характеристиками зубків часнику, сформованих на циліндричному стрижні його головки. Проведеним аналізом отриманих результатів встановлено, що розрахункові значення об'єму, а відповідно й маси зубків зростають із збільшенням не тільки їхніх розмірів, а й форми, яка загалом залежить від сорту та індексу головки часнику.

Теоретично доведено, що максимальні значення об’єму і маси притаманні зубкам 3 найбільшою висотою, а мінімальні, навпаки, - 3 найменшою висотою.

Ключові слова: зубок часнику, аналітична модель, розмір, об’єм, маса, центр ваги.

Semen Ya., Ponomarenko O., Krupych O., Levko S. Analytical model of garlic clove with central rod

The article presents the results of scientific research and comparative analysis of the analytical models of different forms of garlic cloves, as a basis for creating adaptive working bodies for their capture and forced-oriented insertion into the soil. The theoretical research was carried out and a model of a garlic clove, formed on the central stem of a garlic head was proposed. It is considered in the Cartesian coordinate system as a part of a sphere of corresponding radius, the volume of which is limited by two meridional planes and is perpendicular to the other two, taking into account the diameter of the Central rod of the garlic head, on which the cloves are formed, and which is considered as a cylinder of a certain radius and height.

The analytical dependences are obtained to find the mass of a garlic clove formed on the central rod of the garlic head, taking into account the homogeneity of bodies of equal density separately for the central rod and the tooth, the center of gravity of which lies in the plane of symmetry bisecting the tooth.

The calculation scheme is given and analytical dependences are obtained to determine the coordinates of the center of gravity of the garlic clove using the method of positive and negative areas, taking into account the coordinates of the centers of gravity of the circular sectors of the clove and the central cylindrical rod in their arbitrary cross section. followed by a tabular display of the obtained values.

Some results of theoretical researches on definition of the size-mass indicators of the garlic cloves formed on a cylindrical core are obtained and their analysis is carried out. It is established that the calculated values of the volume and, consequently, the mass of cloves increase by increasing not only their size but also the shape, which generally depends on the variety and index of the garlic head.

It is theoretically proven that the maximum values of volume and mass are inherent in the cloves with the highest height, and the minimum, on the contrary - with the lowest height. The value of the coordinates of the garlic clove gravity center depends on its size and shape, and the impact of each of the studied parameters is difficult to assess separately.

Key words: garlic cloves, analytical model, size, volume, weight, center of gravity. 
Постановка проблеми. Зважаючи на різноманітність форм, мінливість розмірно-масових показників, фізико-механічних властивостей та характеристик зубків часнику, розглядати пристосованість їх до орієнтованого поштучного садіння денцем вниз, а ростком вгору механізованим способом необхідно тільки після створення аналітичних моделей, які враховують морфологічні особливості кожного сорту часнику [9; 15]. Без такої умови неможливо домогтися належної якості механізованого садіння вказаної сільськогосподарської культури, оскільки більшість сучасних машин працює за принципом сівалок, після відокремлення від садильних апаратів яких зубки часнику падають під дією власної ваги i хаотично розподіляються в борозенці [11]. Це пов'язано 3 тим, що під час створення таких машин більше уваги приділяли розмірам, масі та формам зубків часнику, оскільки умову їх орієнтованого розподілу в грунті не брали до уваги.

Але на сучасному рівні розвитку наукової думки, техніки й технологій процес орієнтованого садіння окремих сільськогосподарських культур, зокрема й часнику, знову стає актуальним, на що вказують наукові праці $[5 ; 6 ; 10 ; 12 ; 16]$. I якщо проблема безпосереднього встромляння зубка часнику в борозенку практично вирішена $[1 ; 2 ; 14$; 16], то питання внутрішньомашинного орієнтування зубка залишається відкритим, що пов'язано також із певними труднощами під час визначення його центра ваги. Очевидно, що це відбувається також і через відсутність достатньої теоретичної бази, хоча в цьому напрямі теж $є$ певні доробки, зокрема наукова праця [13], в якій розглядається наближена аналітична модель зубка часнику без врахування центрального стрижня, на якому сформована головка часнику. Проте для аналізу пристосованості окремих сортів часнику до механізованого садіння доцільно розглянути аналітичні моделі різних форм зубків, що слугуватиме основою для наступного математичного моделювання процесу їх поштучного орієнтованого садіння денцем вниз, а ростком угору.

Аналіз останніх досліджень і публікацій. Переважна більшість наукових праць, пов'язаних із виробництвом часнику, присвячена агротехніці його вирощування та біологічним особливостям сільськогосподарської культури. Зокрема, у наукових працях [7; 15] відзначено, що в стрілкуючих часників у центрі денця між зубками утворюється щільна квіткова стрілка. Під час збирання врожаю стрілку обрізають. Самі ж зубки формуються навколо цієї стрілки, яка відіграє роль центрального стрижня головки часнику. А тому, розглядаючи аналітичну модель зубка часнику, необхідно врахувати також наявність біля нього центрального стрижня.

У науковій праці [13] зубок часнику розглядався частиною кулі певного радіуса $R 3$ центром у точці $O_{1}$. Його об'єм обмежувався двома меридіональними площинами, двогранний кут між якими становив $2 \alpha$, та однією площиною, яка лежала в основі зубка і була перпендикулярною до двох інших. Висота зубка дорівнювала $H$, а сама аналітична модель зубка часнику розглядалася без центрального стрижня.

Проведеними у вказаній статті дослідженнями отримано аналітичні залежності для визначення об'єму, маси та координат центра ваги зубка часнику. Так, для визначення об'єму зубка часнику запропоновано формулу

$$
V=\frac{L}{2 R}\left(R^{2} \cdot H-\frac{R^{3}}{3}+\frac{1}{3}(R-H)^{3}\right),
$$

де $L$ - максимальний розмір зубка за шириною.

Масу зубка часнику визначали, вважаючи його густину $\rho$, кг $/ \mathrm{M}^{3}$, однорідною, тобто:

$$
m=\rho \cdot V=\frac{\rho \cdot L}{2 R}\left(R^{2} H-\frac{R^{3}}{3}+\frac{1}{3}(R-H)^{3}\right) .
$$

Щодо координат центра ваги зубка часнику, то вони визначались інтегруванням площі поперечного перерізу зубка за його висотою $H$ та кутом $\varphi_{0}$, який позначає положення площини поперечного перерізу за вказаною висотою.

За результатами теоретичних досліджень розмірно-масових показників зубків часнику, відображених у науковій праці [13], і даними експериментів [9] встановлено, що для окремих сортів доцільно розглядати аналітичну модель зубків часнику разом із центральним стрижнем, щоб уникнути розбіжностей між теорією $\mathrm{i}$ практикою в цьому питанні.

Постановка завдання. Наше завдання отримати аналітичні залежності, які дають змогу встановити координати центра ваги, об’єм та масу зубків часнику, сформованих на циліндричному стрижні його головки.

Виклад основного матеріалу. Розглянемо зубок часнику, сформований на циліндричному стрижні, як частину кулі з радіусом $R$ (рис. 1) i центром у точці $O_{1}$. Цей об'єм обмежений двома меридіональними площинами, двогранний кут між якими дорівнює $2 \alpha$, та однією площиною, яка лежить в основі зубка і $є$ перпендикулярною до двох інших. Виберемо початок декартової системи 
координат $O x y z$ у вершині зубка. Вісь $O z$ спрямуємо вздовж лінії перетину меридіональних площин, вісь $O y$ лежить у площині симетрії зубка, a вісь $O x$ - перпендикулярна до цієї площини.

Центральний стрижень головки часнику, на якому сформовані зубки, можна розглядати як циліндр певного радіуса $r_{l}$ (рис. 2) висотою $H$ (див. рис. 1).

Частина площі поперечного перерізу стрижня 2 головки часнику на довільній відстані $z$ від початку координат $O$ між меридіональними площинами $є$ площею кругового сектора $A_{z 2}$, що визначається як добуток довжини дуги вказаного сектора і половини радіуса [4], або, згідно 3 поданою на рис. 2 схемою, за формулою

$$
A_{z 2}=\frac{\pi 2 n^{\circ} r_{1}}{180^{\circ}} \cdot \frac{r_{1}}{2}=\frac{2 \alpha r_{1}^{2}}{2}=\alpha r_{1}^{2}
$$

де $2 n^{\circ}$ і $2 \alpha$ - відповідно градусна і радіальна міри дуги сектора.

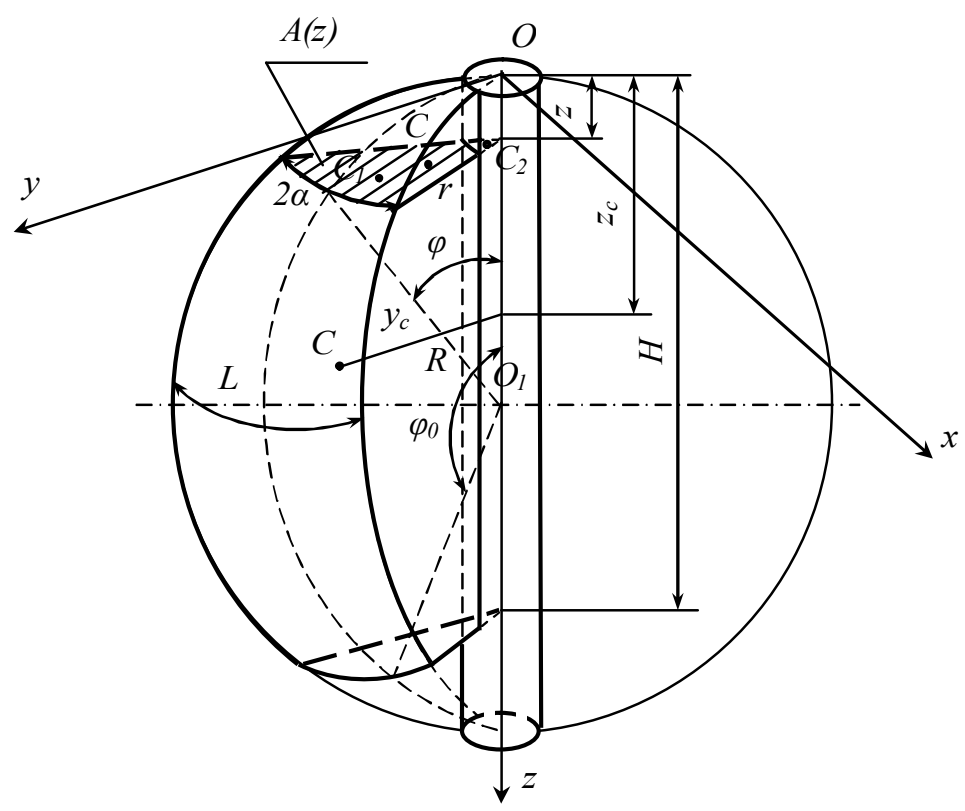

Рис. 1. Форма зубка, сформованого на центральному стрижні головки часнику, і основні його параметри

Fig. 1. Shape of the clove formed on the central rod of the garlic head and its main parameters

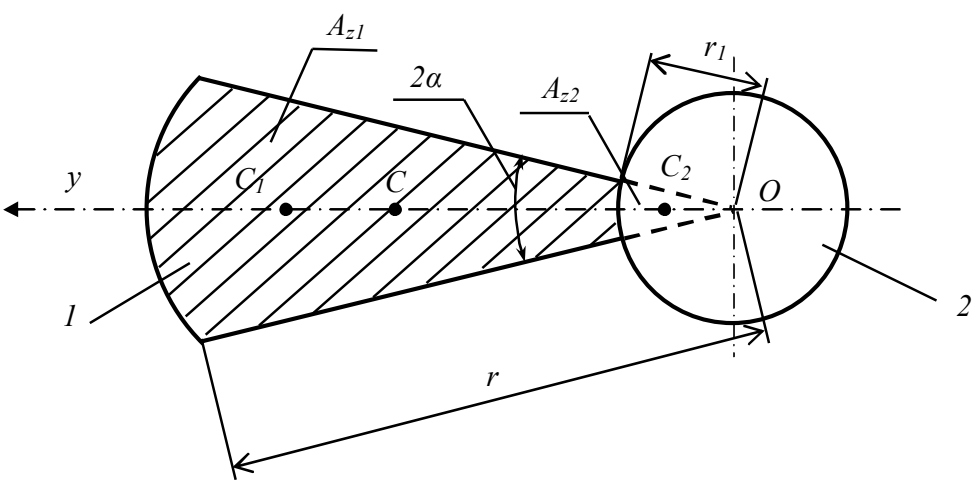

Рис. 2. Схема для розрахунку площі поперечного перерізу зубка часнику: 1 - зубок часнику; 2 - стрижень головки часнику

Fig. 2. Scheme for calculating the cross-section area of a garlic clove: 1 - a garlic clove; 2 - a rod of a garlic head 
Тоді об'єм частини центрального стрижня головки часнику між двома меридіональними площинами визначається як об'єм частини циліндра з площею $A_{z 2}$ і висотою $H$, тобто

$$
V_{1}=A_{z 2} H=\alpha r_{1}^{2} H \text {. }
$$

Об'єм зубка часнику 3 урахуванням наявності центрального стрижня головки часнику визначається як різниця між значенням об'єму $V$ без центрального стрижня [13] та 3 його врахуванням $\left(V_{1}\right)$ :

$$
\begin{aligned}
V_{3} & =V-V_{1}=\frac{L}{2 R}\left(R^{2} \cdot H-\frac{R^{3}}{3}+\right. \\
& \left.+\frac{1}{3}(R-H)^{3}\right)-\alpha r_{1}^{2} H .
\end{aligned}
$$

Масу зубка часнику, сформованого на центральному стрижні його головки, визначаємо 3 урахуванням однорідності тіл однакової густини окремо для зубка і центрального стрижня, користуючись формулою

$$
\begin{gathered}
m=\rho_{3} \cdot V_{3}-\rho_{1} \cdot V_{1}=\frac{\rho_{3} \cdot L}{2 R}\left(R^{2} H-\frac{R^{3}}{3}+\right. \\
\left.+\frac{1}{3}(R-H)^{3}\right)-\rho_{1} \alpha r_{1}^{2} H,
\end{gathered}
$$

де $\rho_{3}, \rho_{1}-$ відповідно густина зубка часнику i центрального стрижня, кг $/ \mathrm{M}^{3}$.

Для визначення координати $y_{\mathrm{c}}$ центра ваги зубка часнику застосовуємо метод додатних i від'ємних площ [17]:

$$
y_{c}=\frac{y_{1} A_{z 1}-y_{2} A_{z 2}}{A_{z 1}-A_{z 2}},
$$

де $y_{1}, y_{2}-$ відповідно координати центрів ваги площ кругових секторів $A_{\mathrm{z1}}$ та $A_{\mathrm{z2}}$.

Згідно з поданою схемою площа кругового сектора $A_{\mathrm{z} 1}$ визначається з умови

$$
A_{z 1}=\alpha r^{2} .
$$

Координата центра ваги кругового сектора $A_{\mathrm{z} 1}$ становить

$$
y_{1}=\frac{2}{3} \cdot \frac{\sin \alpha}{\alpha} r .
$$

За аналогією, площу кругового сектора $A_{z 2}$ можна визначити з умови

$$
A_{z 2}=\alpha r_{1}^{2} .
$$

Тоді координата центра ваги кругового сектора $A_{\text {z2 }}$ становитиме

$$
y_{2}=\frac{2}{3} \cdot \frac{\sin \alpha}{\alpha} r_{1} .
$$

Враховуючи (8)-(11), формула (7) для визначення координати центра ваги зубка часнику $y_{\mathrm{c}} 3$ урахуванням циліндричного стрижня матиме такий вигляд:

$$
\begin{aligned}
& y_{C}=\frac{1}{\alpha\left(r^{2}-r_{1}^{2}\right)} \cdot\left(\frac{2}{3} \cdot \frac{\sin \alpha}{\alpha} r \cdot \alpha r^{2}-\frac{2}{3} \cdot \frac{\sin \alpha}{\alpha} r_{1} \cdot \alpha r_{1}^{2}\right)= \\
& =\frac{1}{\alpha\left(r^{2}-r_{1}^{2}\right)} \cdot\left(\frac{2}{3} \cdot \sin \alpha\left(r^{3}-r_{1}^{3}\right)\right) .
\end{aligned}
$$

Довільне положення перерізу зубка часнику (заштрихована ділянка на рис. 1) на певній відстані $z$ від його вершини можна задати за допомогою змінного кута $\varphi$ між віссю $O z$ i радіусом кулі $R$.

Зважаючи на те, що кут між радіусами зубка по меридіональних площинах становить $2 \alpha$, то формулу (8) для визначення площі поперечного перерізу $A\left(z_{1}\right)$ можна записати таким чином:

$$
A\left(z_{1}\right)=r^{2} \cdot \alpha=\alpha \cdot R^{2} \cdot \sin ^{2} \varphi .
$$

Якщо відстань $z$ виразити через кут $\varphi$, то отримаємо:

$$
\begin{aligned}
& z=R-R \cdot \cos \varphi, \\
& \text { звідки } \quad d z=R \cdot \sin \varphi d \varphi .
\end{aligned}
$$

За аналогією визначаємо висоту $H$ зубка часнику, яка становить:

$$
H=R-R \cdot \cos \varphi_{0} .
$$

У разі, коли відома висота зубка часнику, з формули (16) знаходимо кут $\varphi_{0}$, тобто

$$
\cos \varphi_{0}=\frac{R-H}{R} \text {, звідки } \quad \varphi_{0}=\arccos \left(\frac{R-H}{R}\right)
$$

за умови, що $0 \leq \varphi \leq \varphi_{0}$.

Знайдемо координату $z_{\mathrm{c}}$ центра ваги зубка часнику, скориставшись інтегралом

$$
z_{c}=\frac{1}{V} \int_{0}^{H} z \cdot A\left(z_{1}\right) d z
$$

Підставивши вирази (13)-(15) у формулу (18) і провівши інтегрування, будемо мати:

$$
\begin{gathered}
z_{c}=\frac{1}{V} \int_{0}^{\varphi_{0}}(R-R \cdot \cos \varphi) \alpha \cdot R^{2} \sin ^{2} \varphi \cdot R \cdot \sin \varphi d \varphi= \\
=\frac{\alpha \cdot R^{4}}{V} \int_{0}^{\varphi_{0}}(1-\cos \varphi)\left(1-\cos ^{2} \varphi\right) d(-\cos \varphi)= \\
=-\left.\frac{\alpha \cdot R^{4}}{V}\left(\cos \varphi-\frac{1}{2} \cos ^{2} \varphi-\frac{1}{3} \cos ^{3} \varphi+\frac{1}{4} \cos ^{4} \varphi\right)\right|_{0} ^{\varphi_{0}}= \\
=-\frac{\alpha \cdot R^{4}}{V}\left(\frac{5}{12}-\cos \varphi_{0}+\frac{1}{2} \cos ^{2} \varphi_{0}+\frac{1}{3} \cos ^{3} \varphi_{0}-\frac{1}{4} \cos ^{4} \varphi_{0}\right) \cdot(19)
\end{gathered}
$$

3 урахуванням виразу (1) отримаємо остаточну формулу для визначення координати $z_{\mathrm{c}}$, a саме:

$$
z_{C}=\frac{R}{4} \cdot \frac{5-12 \cos \varphi_{0}+6 \cos ^{2} \varphi_{0}+4 \cos ^{3} \varphi_{0}-3 \cos ^{4} \varphi_{0}}{2-3 \cos \varphi_{0}+\cos ^{3} \varphi_{0}} .
$$

Таким чином, отримані залежності (12) i (20) дають змогу визначити координати центра ваги зубка часнику 3 наявністю центрального стрижня його головки. Їх розв'язок (10) числовим методом Рунге-Кутта [3; 8] у середовищі системи 
Matlab дозволив встановити певний взаємозв'язок між окремими розмірно-масовими показниками i характеристиками зубків часнику, числові значення яких відображено в таблиці.

Таблиця. Результати теоретичних досліджень розмірно-масових показників зубків часнику

Table. Results of the theoretical studies of the size and mass indices of garlic cloves

\begin{tabular}{|c|c|c|c|c|c|c|}
\hline \multicolumn{3}{|c|}{ Вхідні параметри } & \multicolumn{4}{c|}{ Розрахункові значення } \\
\hline висота & радіус & товщина & об’єм & маса & \multicolumn{2}{c|}{ координати центра ваги, м } \\
\cline { 5 - 6 }$H, \mathrm{M}$ & $R, \mathrm{M}$ & $L, \mathrm{M}$ & $V, \mathrm{~cm}^{3}$ & $m, \Gamma$ & $z_{c}$ & $y_{c}$ \\
\hline 0,0200 & 0,0160 & 0,0100 & 1,1638 & 1,32 & 0,0121 & 0,0098 \\
\hline 0,0269 & 0,0269 & 0,0137 & 3,3127 & 3,62 & 0,0168 & 0,0159 \\
\hline 0,0300 & 0,0160 & 0,0200 & 3,3722 & 3,70 & 0,0164 & 0,0091 \\
\hline 0,0277 & 0,0277 & 0,0143 & 3,4005 & 3,73 & 0,0169 & 0,0159 \\
\hline 0,0284 & 0,0286 & 0,0149 & 4,0112 & 4,40 & 0,0178 & 0,0168 \\
\hline 0,0284 & 0,0291 & 0,0165 & 4,1402 & 4,61 & 0,0170 & 0,0168 \\
\hline 0,0285 & 0,0260 & 0,0173 & 4,4418 & 4,94 & 0,0176 & 0,0155 \\
\hline 0,0289 & 0,0303 & 0,0171 & 4,5881 & 5,02 & 0,0176 & 0,0174 \\
\hline 0,0296 & 0,0269 & 0,0177 & 4,9813 & 5,54 & 0,0184 & 0,0156 \\
\hline 0,0300 & 0,0160 & 0,0300 & 5,0594 & 5,60 & 0,0164 & 0,0084 \\
\hline 0,0295 & 0,0315 & 0,0177 & 5,2903 & 5,87 & 0,0186 & 0,0183 \\
\hline 0,0308 & 0,0279 & 0,0182 & 5,4589 & 6,04 & 0,0190 & 0,0166 \\
\hline
\end{tabular}

Як видно з даних таблиці, розрахункові значення об'єму $V$, а відповідно й маси $m$ зубків зростають зі збільшенням не тільки їхніх розмірів, а й форми, яка загалом залежить від сорту та індексу головки часнику. Так, для висоти зубка $H=0,020$ м, товщини $L=0,0100$ м і радіуса $R=0,0160$ м, $V=1,1638 \mathrm{~cm}^{3}$, а $m=1,32$ г. При цьому координати $z_{c}$ i $y_{c}$ його центра ваги відповідно становлять 0,0121 та 0,0098 м. У разі збільшення товщини зубка до 0,020 м, висоти - до 0,0300 м за незмінного радіуса його об'єм зросте до $3,3722 \mathrm{~cm}^{3}$, а маса - до 3,70 г. Характерно, що значення координати $z_{c}$ зросло до 0,0164 , а $y_{c}$ зменшилось до 0,0082 м. Це вказує на те, що форма зубка часнику стала більш округлою.

Теоретичні дослідження показали, що максимальні значення об'єму ( $\left.V=5,4589 \mathrm{~cm}^{3}\right)$ i маси $(m=6,04$ г) притаманні зубкам із найбільшою висотою $(H=0,0308 \mathrm{м})$, а мінімальні $\left(V=1,1638 \mathrm{~cm}^{3}\right.$, $m=1,32$ г), навпаки - 3 найменшою висотою $(H=0,020$ м). Щодо координат центра ваги зубка, то такої закономірності не простежується, оскільки на їхні значення впливають сукупно всі досліджувані вхідні параметри.

Висновки. Теоретичними дослідженнями моделі зубка часнику 3 центральним стрижнем встановлено таке:

1. Розрахункові значення об'єму, а відповідно й маси зубків зростають зі збільшенням не тільки їхніх розмірів, а й форми, яка загалом залежить від сорту та індексу головки часнику.

2. Теоретично доведено, що максимальні значення об'єму і маси притаманні зубкам із найбільшою висотою, а мінімальні, навпаки, - 3 найменшою.

3. Значення координат центра ваги зубка часнику сукупно залежить від його розмірів i форми, причому вплив кожного 3 досліджуваних параметрів важко оцінити роздільно.

\section{Бібліографічний список}

1. Вилка ланцюгово-плунжерного садильного апарата: пат. 137149 Україна: МПК А01С 7/16. № $u$ 2019 02423; заявл. 12.03.19; опубл. 10.10.19, Бюл. № 19.

2. Вилка садильного апарата: пат. 147082 Україна: МПК А01С 7/16. № $u$ 202007640; заявл. 30.11.20; опубл. 07.04.21, Бюл. № 14.

3. Вступ до числових методів: навч. посіб. для вищ. закл. освіти / П. І. Каленюк та ін.; Держ. ун-т «Львів. політехніка». Львів, 2000. 145 с.

4. Довідник 3 елементарної математики / Г. П. Бевз та ін. Київ: Наук. думка, 1976. 390 с.

5. Емельянов П. А., Ибрагимов Н. М. Введение в теорию ориентирования тел техническими средствами в сельскохозяйственных технологических процессах. Пенза: РИО ПГСХА, 2007. 128 с.

6. Кузенко Д. В., Семен О. Я. Машина для садіння зубків часнику. Вісник Львівського національного аграрного університету: агроінженерні дослідження. 2017. № 21. С. 114-118.

7. Кузенко Д. В., Семен О. Я., Гошко З. О., Семен Я. В. Дослідження розмірно-масових показників 
зубків часнику. Збірник наукових статей Луцького національного технічного університету: сільськогосподарські машини. 2018. Вип. 39. С. 86-93.

8. Кухарев О. Н., Ларюшин Н. П. Исследование цепочно-ложечного высаживающего аппарата с ориентирующим устройством для лука-матки. Техника в сельском хозяйстве. 2004. № 2. С. 21-23.

9. Лихацкий В. И. Чеснок. Биология и технология выращивания: практ. пособие. Киев: УСХА, 1990. $96 \mathrm{c}$.

10. Самарский А. А., Гулин А. В. Численные методы. Москва: Наука, 1989. 430 с.

11. Семен О. Я. Аналіз конструкцій машин для садіння часнику. Теорія $i$ практика розвитку агропромислового комплексу та сільських територій: матеріали XVII Міжнар. наук-практ. форуму (м. Львів, 14-16 верес. 2016 р.). Львів, 2016. С. 254-261.

12. Семен О. Я. Обгрунтування способу садіння часнику машиною $з$ ланцюгово-плунжерним садильним апаратом. Перспективи $і$ тендениії розвитку конструкиій та технічного сервісу сільськогосподарських машин $i$ знарядь: матеріали IV Всеукр. наук.-практ. конф. (м. Житомир, 28-29 берез. 2018 р.). Житомир, 2018. C. 27-29.

13. Семен О. Я., Кузенко Д. В., Семен Я. В. Аналітична модель зубка часнику. Збірник наукових прачь Кіровоградського начіонального технічного університету: техніка в сільськогосподарському виробництві, галузеве машинобудування, автоматизачія. Кропивницький: ЦНТУ, 2018. Вип. 31. С. 40-46.

14. Семен Я. В., Семен О. Я. Робочий орган для поштучного орієнтованого садіння зубків часнику. Вчені Львівського начіонального аграрного університету виробництву: каталог інноваційних розробок. Львів, 2019. Вип. 19. С. 57.

15. Снітинський В. В., Ліщак Л. П., Ковальчук Н. І., Ліщак I. О. Часник на фермському полі та присадибній ділянці. Львів: Укр. бестселер, 2010. 110 с.

16. Спосіб механізованого поштучного садіння зубків часнику: пат. 138615 Україна: МПК А01С 7/18. № $u 2019$ 04349; заявл. 22.04.19; опубл. 10.12.19, Бюл. № 23.

17. Теоретична механіка: підручник / В. М. Булгаков та ін. Київ: Аграр. наука, 2014. 560 с.

Стаття надійшла 30.08.2021 